\title{
Psychological Impact of a Pandemic Widespread in Healthcare Workers: The Italian and Swiss Perspective Early After of CoVid-19 Outbreak
}

\section{Laura Uccella}

Ospedale Regionale di Lugano Civico e Italiano

\section{Pietro Majno-Hurst}

Ospedale Regionale di Lugano Civico e Italiano

Sara Uccella ( $\nabla$ sara.uccella@gmail.com )

Istituto Giannina Gaslini https://orcid.org/0000-0003-4164-2125

\section{Luca Jacopo Pavan}

Centre Hospitalier Universitaire de Nice

\section{Stefano Uccella}

Nuovo Ospedale degli Infermi ASL Biella

\section{Cesare Zoia}

Fondazione IRCCS Policlinico San Matteo

Francesco Mongelli

Ospedale Regionale di Lugano Civico e Italiano

\section{Research}

Keywords: COVID-19, pandemic, outbreak, psychology, hospital, healthcare workers, stress, mental health

Posted Date: July 15th, 2020

DOl: https://doi.org/10.21203/rs.3.rs-41724/v1

License: (c) (1) This work is licensed under a Creative Commons Attribution 4.0 International License. Read Full License 


\section{Abstract}

Background. We investigated the COVID19-related psychological impact in healthcare workers three weeks after its onset in Italy and in Italian-speaking regions of Switzerland. All professional groups of public hospitals in Italy and Switzerland were asked to complete a 38 questions online survey investigating demographic, marital and working status, presence of stress symptoms and need for psychological support.

Results. Within 38 hours a total of 3,038 responses were collected. The subgroup analysis identified specific categories at risk according to age, type of work and region of origin. Critical care workers, in particular females, reported an increased number of working hours, decline in confidence in the future, presence of stress symptoms and need for psychological support. People reporting stress symptoms and those with children declared a higher need for psychological support.

Conclusions. The large number of participants in such a short time advocates for a high interest on topic among hospital workers. The COVID19 outbreak could have been and still be a repeated trauma for many health professionals, with risk of future psychiatric sequelae. It is of outstanding importance to implement short and long-term measures to mitigate impact of the emotional burden of this pandemic while at the same time dealing with its clinical challenges.

\section{Background}

The world has been (and is still) experiencing a mass casualty event [1], being stressful and intrusive by affecting daily life and putting adaptive skills to the test. Psychologically, during the early stages of the outbreak we have experienced the so-called alarm stage [2] because of a virus that confined all of us at home (or at work, in the case of health personnels), putting social relationships, freedom and economy at strain. Feelings of inadequacy or insufficiency are common and one can experience a sense of being lost and confused [2]. Moreover, we are still subjected to constantly heavy load of information coming from the mass media and which is not at all times consistent or comprehensive [3].

After the initial stun, anxiety, irritability and restlessness come forth. There are some reactions that can be considered normal: physical reactions like palpitations or difficulty breathing (expression of a sympathetic system activation, not of Coronavirus); cognitive reactions like disorientation, difficulty giving a meaning to the pieces of information received and understanding the real severity of the event; emotional reactions like anguish, stunning, shock, anger, sadness [4-7] and fear of people one can comes across while grocery shopping, walking into a pharmacy or into a hospital (we could even feel stuck or deprived of the desire to carry out daily activities); behavioral reactions (difficulty communicating, hyperactivity, ease to either verbal or physical confrontation, lack of functionality in the work place). One could also experience the inability either to unwind and relax, or to fall asleep or to sleep. 
It is likely that everyone would have experienced marked stress reactions and that some will develop posttraumatic stress disorder (PTSD) [8]. The response to a traumatic event is subjective and dependent on numerous factors such as social relationships that can offer emotional support (friends, family, colleagues) and the kind of working activity [8]. Facing this largescale infectious public health crisis, medical staff are under both physical and psychological pressure or, at least, it can be hypothesized [2, 9]. In this scenario, the mental status of healthcare professionals is dangerously jeopardized, because of both the key and front-line role they play and the risk of becoming infected $[5,8]$.

The aim of this study was to investigate the psychological impact of CoVid-19 outbreak in hospital workers in the first three weeks of outbreak in Italian speaking regions, such as northern Italy, where the European outbreak begun, and southern Switzerland, that followed few days later.

\section{Results}

From 14th March 2020, 8.52 p.m. to 16th March 2020, 10.45 a.m., over a 38 hours period, 3,038 hospital workers completed the survey. The percentage of completed surveys was $97.3 \%$ as 79 subjects did not answer one or more questions.

\section{Demographics, social and working characteristics}

The majority of our respondents were physicians, female and people aged 26-36. Details on age, gender, regions of origin and working characteristics are reported in Table 1 and Fig. 1. 
Table 1

Demographic, social and work characteristics.

\begin{tabular}{|c|c|c|c|}
\hline & & $\mathbf{N}$ & $\%$ \\
\hline \multirow[t]{3}{*}{ Country } & Italy & 2176 & 71.6 \\
\hline & Switzerland & 804 & 26.4 \\
\hline & Not specified & 58 & 2.0 \\
\hline \multirow[t]{3}{*}{ Sex } & Female & 2229 & 73.7 \\
\hline & Male & 795 & 26.3 \\
\hline & Not specified & 14 & 0.4 \\
\hline \multirow[t]{7}{*}{ Age (year-old) } & $18-25$ & 114 & 3.8 \\
\hline & $26-35$ & 1035 & 34.1 \\
\hline & $36-45$ & 996 & 32.8 \\
\hline & $46-55$ & 617 & 20.3 \\
\hline & $56-65$ & 253 & 8.3 \\
\hline & over 65 & 23 & 0.8 \\
\hline & Not specified & 0 & 0 \\
\hline \multirow[t]{10}{*}{ Kind of job in hospital } & Physicians & 1600 & 53.3 \\
\hline & Nurses & 550 & 18.3 \\
\hline & Radiology, intermediate care technicians & 441 & 14.7 \\
\hline & Ambulance services & 87 & 2.9 \\
\hline & Obstetricians & 60 & 2.0 \\
\hline & Administrative & 49 & 1.6 \\
\hline & Technical services & 30 & 1.0 \\
\hline & Hospitality services & 13 & 0.4 \\
\hline & Pharmacy & 7 & 0.2 \\
\hline & Other hospital services & 167 & 5.6 \\
\hline \multirow[t]{2}{*}{ Civil status } & Married & 1313 & 43.3 \\
\hline & Single & 837 & 27.6 \\
\hline
\end{tabular}




\begin{tabular}{|c|c|c|c|}
\hline & & $\mathbf{N}$ & $\%$ \\
\hline & Stable relationship & 672 & 22.2 \\
\hline & Divorced & 172 & 5.7 \\
\hline & Widowed & 25 & 0.8 \\
\hline & Civil Partnership & 13 & 0.4 \\
\hline & Not specified & 6 & 0.1 \\
\hline \multirow[t]{6}{*}{ Family (number of people) } & 1 & 615 & 20.3 \\
\hline & 2 & 769 & 25.4 \\
\hline & 3 & 700 & 23.1 \\
\hline & 4 & 663 & 21.9 \\
\hline & 5 & 184 & 6.1 \\
\hline & $>5$ & 97 & 3.2 \\
\hline \multirow[t]{2}{*}{ Children < 18-year-old in household } & 0 & 1734 & 57.3 \\
\hline & 1 or more & 1304 & 42.7 \\
\hline \multirow[t]{2}{*}{ Elderly > 65-year-old in household } & 0 & 2422 & 80.0 \\
\hline & 1 or more & 616 & 20.0 \\
\hline \multirow[t]{7}{*}{ Years of work in hospital } & $0-1$ years & 207 & 6.8 \\
\hline & $2-5$ years & 623 & 20.5 \\
\hline & $5-10$ years & 634 & 20.9 \\
\hline & $10-20$ years & 858 & 28.3 \\
\hline & $20-30$ years & 478 & 15.8 \\
\hline & $>30$ years & 233 & 7.6 \\
\hline & Not specified & 7 & 0.2 \\
\hline \multirow[t]{4}{*}{ Physical activity } & Once a day & 180 & 5.9 \\
\hline & 4-5 times a week & 185 & 6.1 \\
\hline & 2-3 times a week & 855 & 20.3 \\
\hline & Once a week & 439 & 14.5 \\
\hline
\end{tabular}




\begin{tabular}{|llll|}
\hline & & N & $\%$ \\
\hline \multirow{3}{*}{ Increased number of working hours } & Less than once a week & 295 & 9.7 \\
\cline { 2 - 4 } & None at all & 1081 & 35.6 \\
& No & 2110 & 70.0 \\
\cline { 2 - 4 } & Up to 10 hours & 673 & 22.3 \\
\cline { 2 - 4 } & Up to 20 hours & 161 & 5.3 \\
\cline { 2 - 4 } & Up to 30 hours & 40 & 1.3 \\
\cline { 2 - 4 } & $>30$ hours & 30 & 1.0 \\
\hline Characteristics are expressed as absolute value and percentage & & \\
\hline
\end{tabular}

Seventy percent of people declared not to have any additional work due to the CoVid-19 emergency. Among people who responded to have to work more, $59 \%$ was ambulance personnel, $38 \%$ nurses, $36 \%$ administrative personnel and $30 \%$ physicians. Dividing for department, $60 \%$ of workers in intensive care unit, $50 \%$ of anesthesiologists, $50 \%$ of the staff in emergency department and $46 \%$ of general practitioners declared to work more than normal. People working in hospital in the last 20-30 years had the higher percentage of increased number of working hours. By grouping working categories in critical care (intensive care unit, emergency department, anesthesiology, ambulance service), surgery (otorhinolaryngology, neurosurgery, orthopedics, cardiac surgery, urology, gynecology) and general practitioners, surgery resulted to be the group that had to reduce the most the number of working hours (C.I. 25.0-31.7\%), whereas the other two groups had to work more (C.I 44.7-52.3\% for critical care and $40.8-54.8 \%$ for general practitioners). On the contrary, 2256 (76.4\%) people did not have to reduce their working-hours because of CoVid-19 emergency, while $308(10.4 \%)$ had to reduce the work up to ten hours per week, 92 (3.1\%) up to 20 hours per week, 121 (4.1\%) up to 30 hours per week. One-hundred and fifty (5.1\%) people had to be quarantined and $24(0.8 \%)$ reported to get infected with the virus. Twenty-three percent of physicians actually declared to have to work less than normal. As expected, people working in southern Italy (C.I. 16.6-22.8\%), where the CoVid-19 did not spread yet, declared to work less than their counterpart in northern Italy (C.I. 31.1-35.6\%) and Switzerland (C.I. 33.5-48.4\%).

\section{Stress symptoms}

Details are reported in Table 2. The decision tree analysis showed a higher probability of sleeping less than normal (accuracy 62.2\%) in people aged $>30$ from Italy and having one or more children in their family. In particular, nurses of the critical care with history of anxiety problems were the category at higher risk to suffer from sleep disturbances (accuracy $82.9 \%$ ). 
Table 2

Stress symptoms.

\begin{tabular}{|c|c|c|c|}
\hline & & $\mathbf{N}$ & $\%$ \\
\hline \multirow[t]{5}{*}{ Sleeping } & Sleep less than usual & 1203 & 39.6 \\
\hline & Sleep the same number of hours but they feel less rested & 953 & 31.4 \\
\hline & No change & 678 & 22.3 \\
\hline & Sleep more than usual & 172 & 5.7 \\
\hline & Sleep the same number of hours but they feel more rested & 30 & 1.0 \\
\hline \multirow[t]{5}{*}{ Eating } & No change & 1164 & 38.4 \\
\hline & More than usual & 715 & 23.6 \\
\hline & Less than usual & 529 & 17.4 \\
\hline & Same quantity of food, but healthier & 223 & 7.3 \\
\hline & Same quantity but more unhealthy food & 402 & 13.3 \\
\hline \multirow[t]{5}{*}{ Smoking } & Never smoked & 1820 & 59.9 \\
\hline & Started before the last three weeks & 652 & 21.5 \\
\hline & Quitted before the last three weeks & 487 & 16.1 \\
\hline & Started in the last three weeks & 27 & 0.9 \\
\hline & Quitted smoking in the last three weeks & 41 & 1.4 \\
\hline
\end{tabular}

Eating habits changed in 1869 (61.5\%) hospital workers and 679 (22.3\%) declared to be active smokers. Among them, 268 subjects (39.5\%) had to increase the number of cigarettes (cigars, e-cigarettes, etc.) smoked per day in the last three weeks. One-thousand-six-hundred-fifty-seven people (55.1\%) stated to drink alcohol occasionally or regularly. Among them, 57 (3.4\%) started in the last three weeks and 255 (15.3\%) declared that their consumption had increased in the last three weeks. The vast majority of respondents said that they never used drugs $(2756,91.1 \%)$, whereas 129 quitted before the last three weeks $(4.2 \%)$ and three $(0.1 \%)$ within the last three weeks.

Almost a half of our sample (1538 people, $50.6 \%$ ) declared to have a chronic health problem, of whom roughly a quarter (348 subjects, 22.6\%) experienced a worsening in their chronic health condition. Appearing of new symptoms were reported by 969 individuals (31.9\%) and, more specifically, 285 (9.4\%) experienced palpitations, 276 (9.1\%) respiratory symptoms, 124 (4.1\%) pain and $285(9.4 \%)$ other symptoms. 
Regarding "How much free-time do you spend looking at information about CoVid-19?", 654 people (21.1\%) declared less than an hour per day, 1112 (36.7\%) between one and two hours, $1094(36.1 \%)$ more than two hours per day and $173(5.7 \%)$ did not look at such information. Nearly half of our sample (1369 subjects, $45.1 \%$ ) reported to talk about the CoVid-19 outbreak with family, friends and colleagues for more than two hour per day, 1116 (36.8\%) between one and two hours, 505 (16.7\%) for less than an hour and $44(1.4 \%)$ did not spend time speaking about CoVid-19.

Among people with children, 451 (26.0\%) reported excessive crying or unusual irritation, 308 (17.7\%) noticed a behavioral regression, $186(10.7 \%)$ noticed unusual headaches or other unexplained pain sensations, 752 (43.3\%) reported anxiety and concern about the CoVid-19 outbreak.

Physical activity was reduced in 1428 (47.0\%) subjects in the last three weeks, while $125(6.3 \%)$ said they could increase it. The physical contacts diminished in 2875 people $(94.9 \%)$, increased in 12 people $(0.4 \%)$ and did not change in 143 subjects (4.7\%). As opposed to physical contacts, virtual contacts increased for 1960 individuals (64.6\%), diminished for 175 subjects (5.8\%) and did not change for 898 people (29.6\%). Hobbies and other activities undertaken for pleasure or relaxation diminished for 1908 persons $(63 \%)$, increased for 260 persons ( $8.6 \%$ ) and did not change for 862 people (28.4\%). A statistically significant correlation was found between increased number of working hours and stress symptoms such as eating less or more, sleeping less or not feeling relaxed, drinking or smoking more.

One thousand two-hundred and eighty-four people (42.4\%) declared they are separated from their family because of CoVid-19.

\section{Need for psychological support and confidence in the future}

In the last three weeks 706 people perceived to need a specialized psychological support (23.3\%). Confidence in the future was diminished for 1404 persons (46.3\%), increased for 246 subjects (8.1\%) and did not change for 1384 people (45.6\%). People feeling the need of professional psychological support were more often female (C.I. $24.8-28.3 \%$ vs. $13.0-17.1 \%$ for females and males respectively), in a couple (C.I. 23.7-27.4\%) or subjects reporting stress symptoms (Fig. 2). Long-career workers (C.I. 7.1-15.0\%) and ambulance services (C.I. 7.5-20.8\%) expressed less often the need for psychological support. As reported in Fig. 3, different professional categories expressed different psychological support need. People stating an increased confidence in the future were more often males (C.I 5.4-11.6\% vs. 9.2-30.2\% for females). As expected, among people with diminished confidence in the future there was a higher prevalence of females (C.I $34.2-60.6 \%$ vs. $32.6 \%-45.7 \%$ for males).

Plotting the data by country, the confidence in the future in the last three weeks was more lowered in people from Italy as compared to Switzerland (C.I. $46.0-52.3 \%$ vs. $34.2-41.1 \%$ ). This difference did not change by plotting data either by work category or by age or length of career. Surprisingly, by plotting the decreased confidence in the future for the type of hospital work, all categories were equally affected except of ambulance services (C.I. $16.1-33.6 \%$ vs. $40.0-51.2 \%$ for other categories). 
Finally, history of anxiety resulted to be an independent factor associated to a reduced confidence in the future (C.I. $47.7-60.2 \%$ vs. $37.6-42.5 \%$ with and without history of anxiety respectively).

\section{Discussion}

The present study highlights elevated stress levels in a cohort of Italian-speaking hospital workers during the early phases of the outbreak of Sars-Cov2 infection due to the novel CoVid-19. To best of our knowledge, our study was the earliest to explore the psychological impact of this novel pandemic on healthcare workers among Italian speaking countries (Italy and Italian-speaking regions of Swizerland).

Hospital workers have engaged with catastrophic events caused by the massive CoVid-19 outbreak [11]. Beyond demanding clinical and logistic issues, hospital employees have to deal with their own physical and mental health [11-15]. Work-related stress has shown to impact physician's mental health, patients' care quality and the efficiency of the healthcare system [16]. Consequences in terms of mental health in the context of maxi-emergency situations may be even more pronounced than normal. Feelings of inadequacy, insufficiency, lostness or confusion are common and hospital workers may even experience negative behavioral reactions, depression and illness, possibly leading to lack of effectiveness and efficiency at work [4-6].

The large number of responses and the small percentage of uncompleted surveys $(2,7 \%)$ in less than 40 hours advocates for a high interest in the subject among healthcare personnel. This may also express the need among healthcare workers to communicate, to be heard and understood that encompasses professional attitude and rules of conduct and touches the psyche and emotions.

More than $50 \%$ of survey participants were physicians, probably because the survey promoters were physicians both in southern Switzerland and northern Italy and invitations to participate were sent through personal contacts and social media. However, the high turnout rate of several other hospital categories could mirror the concept that the present is a common burden among all health workers.

\section{Demographics, social and working distribution}

The population aged 26-45 represents the majority of the sample, probably because it is are more likely to be reached by social media. The small number of people aged between 18-25 is likely to reflect the relatively low number of very young people working in hospitals as confirmed by the fact that medical trainees under 26-years of age are not yet medical doctors in Italy and Switzerland. The distribution of worked years in hospital roughly reflects the age distribution.

In our sample, two thirds of survey participants were female. This could be interpreted according to the fact that a growing percentage of medical professionals is represented, nowadays, by women. It could be also speculated that gender differences may play a role in stress perception and management. Hormonal differences in hypothalamic-pituitary-adrenal axis and autonomic nervous system response are wellknown. It has been hypothesized that females tend to experience more frequently anxious and depressive 
states (also with physical symptoms), being more aware of potential stressors rather than men [17] In our sample, percentages of married, single, divorced etc. and other demographic characteristics were grossly comparable to the Swiss and Italian population $[18,19]$.

Nearly one third of hospital workers in our study had to increase their working activity. It represents the first, well-recognized stress factor, proportional to the increase of worked hours [20]. As expected, health care professionals having to increase their working hours, are those employed either in critical care settings or general practitioners, the first categories having to be confronted with the CoVid-19 emergency. On the other hand, in several hospitals in northern Italy and southern Switzerland a dramatic reduction of surgical elective cases and outpatient clinic activity has been deemed necessary to contain virus spread and, as a consequence, surgeons as a category experienced a reduction in working hours. Notwithstanding, a reduction of working hours should not be considered less insidious, as it could nonetheless jeopardize the mental status and could lead to depressive symptoms, hopelessness and uselessness [21].

\section{Stress symptoms}

Sleep disturbances can be caused by stress and be related to post-traumatic stress disorder and the first response is generally considered a period of arousal and wakefulness [22, 23]. A great proportion of hospital workers in our study declared to sleep less than normal and to feel less restored by sleep in general, presumably as a reaction to the stressful circumstances and it is likely to reflect the high prevalence of sleep arousal and anxiety symptoms in healthcare professionals.

The correlation analysis showed a relatively higher prevalence of stress symptoms among young professionals with at least one child to care of, as response of having to face the CoVid-19 outburst emergency.

Similarly, an increase or a decrease in in food intake may mirror a reaction to a stressful situation and, actually, in our sample, only $40 \%$ of the interviewed reported no change [24]. Moreover, among smokers, there was a high proportion of participants that declared to have increased the number of cigarettes per day in the first three weeks since the outbreak onset. A smaller, but significant proportion of people reported an increase in alcohol consumption. All these behavioral changes can be considered stress symptoms $[25,26]$. In our study, a strong correlation was found between the above-mentioned symptoms and the need for psychological support. In fact, people reporting such symptoms were more prone to report the need for psychological support. As far as we know, this is the first time that such a need is quantified within the emergency of CoVid-19.

\section{Need for psychological support}

Interestingly, people with children reported the most stressful answers and felt the need for professional psychological support more often than their not-parenting peers. Despite some might consider this obvious, such data are nonetheless of outstanding importance, as hospital employees are often in the fertile age range. In the setting of a massive viral outbreak, hospital caregivers experience important 
issues in caring for their children because of the closure of schools and of other facilities. Parents probably do not experience only the stress related to future uncertainty but also the fear of getting infected and possibly transmit such an infectious disease to their offspring. Specifically, CoVid-19 has shown to be particularly infective also for hospital workers and casualties have been reported among hospital staff [12]. Coherently, many hospital workers with children (nearly 95\%) declared to have reduced their physical contacts with other family components.

Almost all subcategories of hospital workers perceive the stress related to the outbreak equally. Only longcareer workers and ambulance service personnel reported to need psychological support less as compared to other categories. This may be explained by the high level of experience and long-standing training in stress management in long-career employees. On the other hand, emergency services personnel may be used to address stressful situations, as they are part of a coordinated and ordered emergency response and have to constantly handle very high levels of stress [27, 28].

The actual outbreak could be a repeated trauma for many healthcare categories, putting them at risk of psychiatric sequelae such as PTSD $[8,29]$. The present outbreak could be a repeated trauma for many health professionals and could put them at risk of developing psychiatric sequelae such as posttraumatic stress disorder. It is of outstanding importance in such a critical situation to promptly implement measures to mitigate the impact of the emotional burden of the present COVID-19 pandemic while at the same time dealing with its clinical challenges $[2,4]$.

In particular, positive behaviors such as healthy eating, sport practicing and sleeping an adequate number of hours have shown to impact and reduce the impact of stress [30]. Many other strategies have also shown to be effective, such as the implementation of debriefing sessions and group therapies to share experiences and relieve the sorrow related to challenging and stressful situations. Programs of deescalation of tension through mindfulness techniques could be also cost-effective and easily implemented in routine practice to prevent future development of acute and chronic PTSD, major depression or suicidal behaviors [31, 32].

Our study has some limitations. Firstly, our data were collected in a completely anonymized and we have not certainty on their truthfulness. Nonetheless, our data denote a certain internal coherence, that can be interpreted as trustworthiness. Secondly, it can be considered an initial evaluation and further studies in different time points of the outbreak are needed to understand the impact of CoVid-19 emergency on healthcare workers' psychology and mental health. Thirdly, our sample is mainly (but not exclusively) composed of physicians and that could lead to a selection bias among the different hospital working categories and may not entirely reflect the actual global status.

\section{Conclusions}

Perceived psychological burden in hospital workers has to be considered relevant since the early phases of an infectious disease widespread. CoVid-19 outbreak has, therefore, to be considered as a major stress event, able to threaten the physiological and psychological integrity of individuals, in particular healthcare 
professionals. Counseling, psychological support and awareness on this subtle threat to hospital workers should not be overshadowed, as even hospital efficiency may be jeopardized.

\section{Methods}

Aim of the present study was to explore the psychological effect of CoVid-19 outbreak among healthcare workers in Italian speaking regions three weeks after the outbreak.

\section{Study design and participants}

Between 14th and 16th March 2020, hospital workers of different public hospital in Switzerland and Italy were asked to participate a survey regarding the psychological impact of CoVid-19 outbreak on the daily life, at the time point when the virus mainly widespread in northern Italy, Iran and China, but hadn't assumed an extensive dissemination in Switzerland yet. Participants were personally invited by the Authors to answer the questionnaire via social media (either Facebook or WhatsApp) and agreed voluntarily to the questionnaire being fulfilled. All data were anonymized, so that, according to the actual Swiss legislation, no informed consent or institutional review board approval were needed. All staffed hospital teams were included, such as nurses, physicians, obstetricians, pharmacists, technical service, hospital canteen, laundry and others.

\section{Questionnaire}

The questionnaire (see Suppl. material available on line) was built on Google Forms (https://www.google.com/forms/about/) and consisted in 38 questions investigating demographic, social and working status (gender, age, civil status, total number of people and people $>65$-year-old in the family, worked years in hospital, profession, department, working time changes since the beginning of the outbreak, chronic diseases worsening, alcohol drinking, drugs consumption, social media use, hobbies, history of anxiety and medical therapy), stress symptoms (alimentary behavior changes, new symptoms occurring in the last three weeks, smoking status and number of cigarettes/day, number of hours spent to get information and to speak about the CoVid-19 widespread, detachment from family due to the quarantine, stress behaviors in children, changes in physical activities, change in physical contacts) and need for psychological support (actual perception of the need of qualified psychological support and overall trust in the future). We decided to not use validated questionnaires because they did not guarantee flexibility and rapidity of use; furthermore explorative surveys are a method already adopted for other researches about pandemics [8]. All data were collected on an Excel database (Microsoft Excel ${ }^{\circledR}$ 2019) and analyzed.

\section{Statistical methods}

Statistical analysis was performed using the open source packages "Pandas," "NumPy," "SciPy," "Seaborn," and "PyMC" for Mac Os X versions 0.23.0, 11.1.3, 1.1.0, 0.8.1, and 2.3.6, respectively. Our analysis was based on highly credible intervals (C.I.) of parameter estimates (*); statistical significance was considered achieved whenever credible intervals would be non-overlapping. In order to compare 
proportions in different sub-populations, we performed a Bayesian estimate of the parameter distribution for a Bernoulli stochastic variable using a non-informative uniform prior. The posterior was then plotted in order to have a graphical overview, and credible intervals were computed by assessing the highest density interval ( $\mathrm{HDI})$ at $95 \%$. Only as a reference, whenever two proportions had to be compared, we used also a two-tail $\mathrm{P}$ test computation based on classic proportion comparison using chi-square. Statistical significance was considered $p<0.05$. All MCMC runs were checked for adequacy on the basis of RafteryLewis diagnostics and by visually inspecting Z score plots. MCMC runs were for 40,000 iterations with a 5,000-iteration burn-in [10].

\section{Declarations}

\section{Declarations}

\section{Ethics approval and consent to participate}

The study was conducted in full agreement with the national and international regulations, and the Declaration of Helsinki (2000). Participants' personal information, including names, were kept anonym to maintain and protect privacy and confidentiality of data. All participants were fully informed about the study requirements and were required to accept the data sharing and privacy policy before participating in the study. The anonymous nature of our survey did not allow tracing in any way sensitive personal data. Therefore, the present study did not require approval by Ethics Committee.

\section{Consent for publication}

Not applicable.

\section{Data availability}

Raw data supporting the conclusions of this manuscript will be made available by the authors, without undue reservation, to any qualified researcher.

\section{Competing interest}

The authors have no conflict of interest to declare.

\section{Funding}

The authors received no funding to carry the present research.

\section{Acknowledgements}

The authors acknowledge all healthcare workers and, among them, the ones who participated into the survey.

\section{Author contributions}


LU, SaU and LJP designed the study. LU was involved in constructing the dataset, interpreting data and drafting the manuscript. PMH, FM, StU, CZ and LJP helped in data collection and revising the final questionnaire. All authors discussed the results and commented on the manuscript.

\section{Authors' information}

LU is an Emergency Medicine specialist (MD, PhD) who received a 4-year-special-training in Cognitive Behavioral Therapy at the Cognitive Behavioral Therapy School of Milan (https://studicognitivi.it). SU (MD) is a psychiatrist and neurologist trained in developmental medicine. All the authors have scientifically and clinically shared working experience, have published past researches on impacted journals and are committed to ameliorate healthcare workers job conditions.

\section{References}

1. Sun P, Lu X, Xu C, Sun W, Pan B. Understanding of COVID-19 based on current evidence. J Med Virol. 2020;92(6):548-51.

2. Chen Q, Liang M, Li Y, Guo J, Fei D, Wang L, He L, Sheng C, Cai Y, Li X, Wang J, Zhang Z. Mental health care for medical staff in China during the COVID-19 outbreak. Lancet Psychiatry. 2020;7(4):e15-6.

3. Holmes EA, O'Connor RC, Perry VH, Tracey I, Wessely S, Arseneault L, Ballard C, Christensen H, Cohen Silver R, Everall I, Ford T, John A, Kabir T, King K, Madan I, Michie S, Przybylski AK, Shafran R, Sweeney A, Worthman CM, Yardley L, Cowan K, Cope C, Hotopf M, Bullmore E. Multidisciplinary research priorities for the COVID-19 pandemic: a call for action for mental health science. Lancet Psychiatry. 2020;7(6):547-60.

4. Jacobowitz W, Moran C, Best C, Mensah L. Post-Traumatic Stress. Trauma-Informed Care, and Compassion Fatigue in Psychiatric Hospital Staff: A Correlational Study. Issues Ment Health Nurs. 2015;36(11):890-9.

5. Xiao H, Zhang Y, Kong D, Li S, Yang N. The Effects of Social Support on Sleep Quality of Medical Staff Treating Patients with Coronavirus Disease 2019 (COVID-19) in January and February 2020 in China. Med Sci Monit. 2020 Mar;5:26:e923549.

6. Weinberg A, Creed F. Stress and psychiatric disorder in healthcare professionals and hospital staff. Lancet. 2000 Feb;12(9203):533-7. 355(.

7. Li Z, Ge J, Yang M, Feng J, Qiao M, Jiang R, Bi J, Zhan G, Xu X, Wang L, Zhou Q, Zhou C, Pan Y, Liu S, Zhang H, Yang J, Zhu B, Hu Y, Hashimoto K, Jia Y, Wang H, Wang R, Liu C, Yang C. Vicarious traumatization in the general public, members, and non-members of medical teams aiding in COVID19 control. Brain Behav Immun. 2020 Mar 10.

8. Brooks SK, Webster RK, Smith LE, Woodland L, Wessely S, Greenberg N, Rubin GJ. The psychological impact of quarantine and how to reduce it: rapid review of the evidence. Lancet. 2020;14(10227):912-20. 395(. 
9. Kisely S, Warren N, McMahon L, Dalais C, Henry I, Siskind D. Occurrence, prevention, and management of the psychological effects of emerging virus outbreaks on healthcare workers: rapid review and meta-analysis. BMJ. 2020 May;5:369:m1642.

10. Kruschke JK. Bayesian estimation supersedes the t test. J Exp Psychol Gen. 2013 May;142(2):573603.

11. Zhu N, Zhang D, Wang W, Li X, Yang B, Song J, Zhao X, Huang B, Shi W, Lu R, Niu P, Zhan F, Ma X, Wang D, Xu W, Wu G, Gao GF, Tan W. China Novel Coronavirus Investigating and Research Team. A Novel Coronavirus from Patients with Pneumonia in China, 2019. N Engl J Med. 2020;20(8):727-33. 382(.

12. Schwartz J, King C-C, Yen M-Y. Protecting Health Care Workers during the COVID-19 Coronavirus Outbreak -Lessons from Taiwan's SARS response. Clin Infect Dis. 2020 Mar 12.

13. The Lancet null. COVID-19: protecting health-care workers. Lancet. 2020;21(10228):922. 395(.

14. Kang L, Li Y, Hu S, Chen M, Yang C, Yang BX, Wang Y, Hu J, Lai J, Ma X, Chen J, Guan L, Wang G, Ma $\mathrm{H}$, Liu Z. The mental health of medical workers in Wuhan, China dealing with the 2019 novel coronavirus. Lancet Psychiatry. 2020;7(3):e14.

15. Liem A, Wang C, Wariyanti Y, Latkin CA, Hall BJ. The neglected health of international migrant workers in the COVID-19 epidemic. Lancet Psychiatry. 2020;7(4):e20.

16. Rasool SF, Wang M, Zhang Y, Samma M. Sustainable Work Performance: The Roles of Workplace Violence and Occupational Stress. Int J Environ Res Public Health. 2020;17(3):01.

17. Seo D, Ahluwalia A, Potenza MN, Sinha R. Gender differences in neural correlates of stress-induced anxiety. J Neurosci Res. 2017 02;95(1-2):115-25.

18. Istat.it Popolazione e famiglie [Internet]. [cited 2020 Jul 1]. Available from: https://www.istat.it/it/popolazione-e-famiglie?dati.

19. Statistik B. für. Bundesamt für Statistik [Internet]. [cited 2020 Jun 29]. Available from: https://www.bfs.admin.ch/bfs/de/home.html.

20. Wong K, Chan AHS, Ngan SC. The Effect of Long Working Hours and Overtime on Occupational Health: A Meta-Analysis of Evidence from 1998 to 2018. Int J Environ Res Public Health. 2019 $13 ; 16(12)$.

21. Nagae M, Sakamoto M, Horikawa E. Work-sharing and male employees' mental health during an economic recession. Occup Med (Lond). 2017 Dec;67(8)(2):648-51.

22. Fan F, Zhou Y, Liu X. Sleep Disturbance Predicts Posttraumatic Stress Disorder and Depressive Symptoms: A Cohort Study of Chinese Adolescents. J Clin Psychiatry. 2017 Jul;78(7):882-8.

23. Sanford LD, Suchecki D, Meerlo P. Stress, arousal, and sleep. Curr Top Behav Neurosci. 2015;25:379410.

24. Ulrich-Lai YM, Fulton S, Wilson M, Petrovich G, Rinaman L. Stress exposure, food intake and emotional state. Stress. 2015;18(4):381-99. 
25. Damron KR. Review of the Relationships Among Psychosocial Stress, Secondhand Smoke, and Perinatal Smoking. J Obstet Gynecol Neonatal Nurs. 2017 Jun;46(3):325-33.

26. Ramchandani VA, Stangl BL, Blaine SK, Plawecki MH, Schwandt ML, Kwako LE, Sinha R, Cyders MA, O'Connor S, Zakhari S. Stress vulnerability and alcohol use and consequences: From human laboratory studies to clinical outcomes. Alcohol. 2018;72:75-88.

27. Berge JM, Tate A, Trofholz A, Fertig AR, Miner M, Crow S, Neumark-Sztainer D. Momentary Parental Stress and Food-Related Parenting Practices. Pediatrics. 2017 Dec;140(6).

28. Carley S, Mackway-Jones K, Donnan S. Major incidents in Britain over the past 28 years: the case for the centralised reporting of major incidents. J Epidemiol Community Health. 1998 Jun;52(6):392-8.

29. Bloomfield MAP. Trauma and post-traumatic stress disorder: children should be seen and heard. Lancet Psychiatry. 2019;6(3):193-4.

30. Carmassi C, Gesi C, Corsi M, Cremone IM, Bertelloni CA, Massimetti E, Olivieri MC, Conversano C, Santini M, Dell'Osso L. Exploring PTSD in emergency operators of a major University Hospital in Italy: a preliminary report on the role of gender, age, and education. Ann Gen Psychiatry. 2018;17:17.

31. Dalton J, Thomas S, Harden M, Eastwood A, Parker G. Updated meta-review of evidence on support for carers. J Health Serv Res Policy. 2018;23(3):196-207.

32. Sripada RK, Bohnert KM, Ganoczy D, Blow FC, Valenstein M, Pfeiffer PN. Initial group versus individual therapy for posttraumatic stress disorder and subsequent follow-up treatment adequacy. Psychol Serv. 2016;13(4):349-55.

\section{Figures}




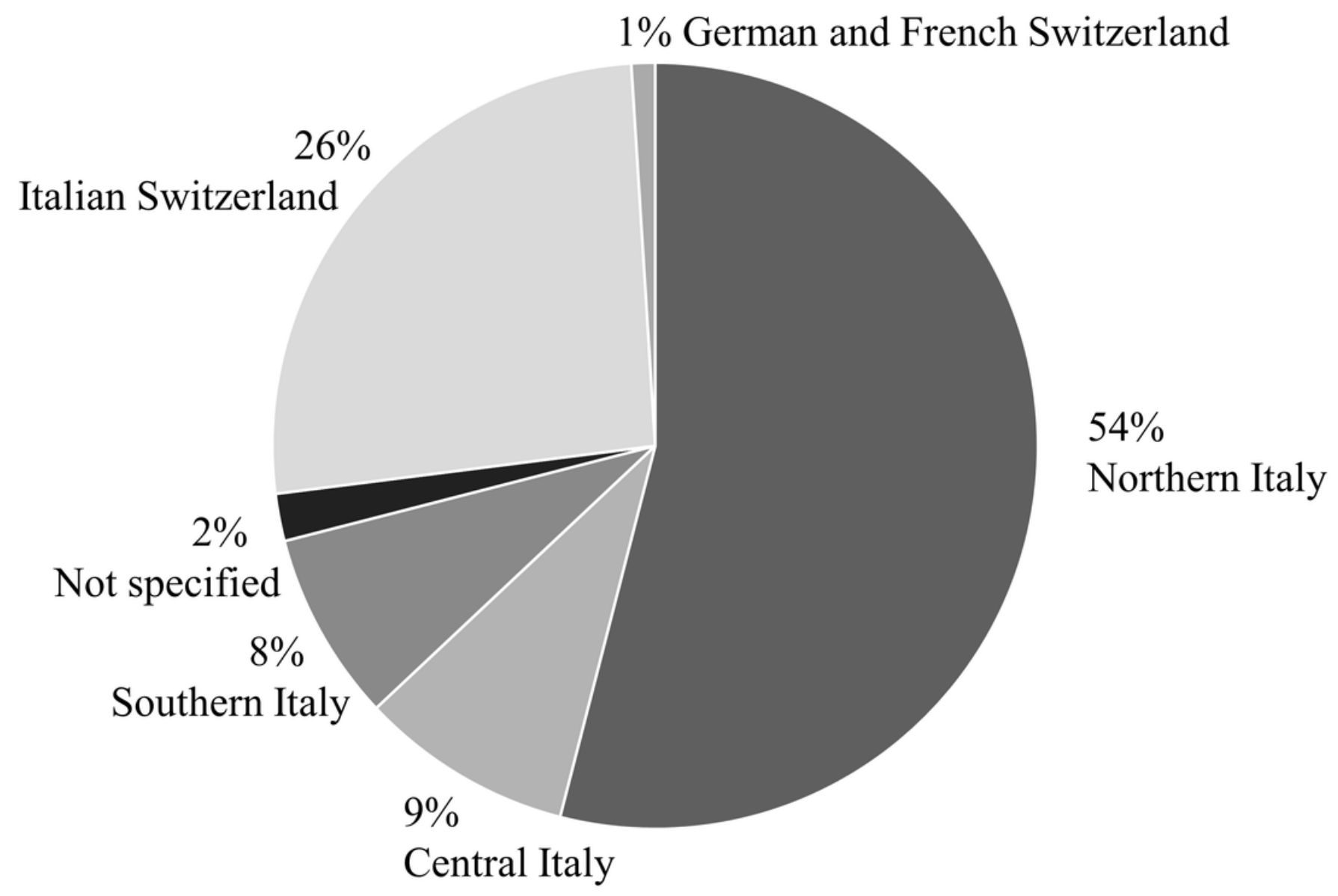

Figure 1

Participants' regions 


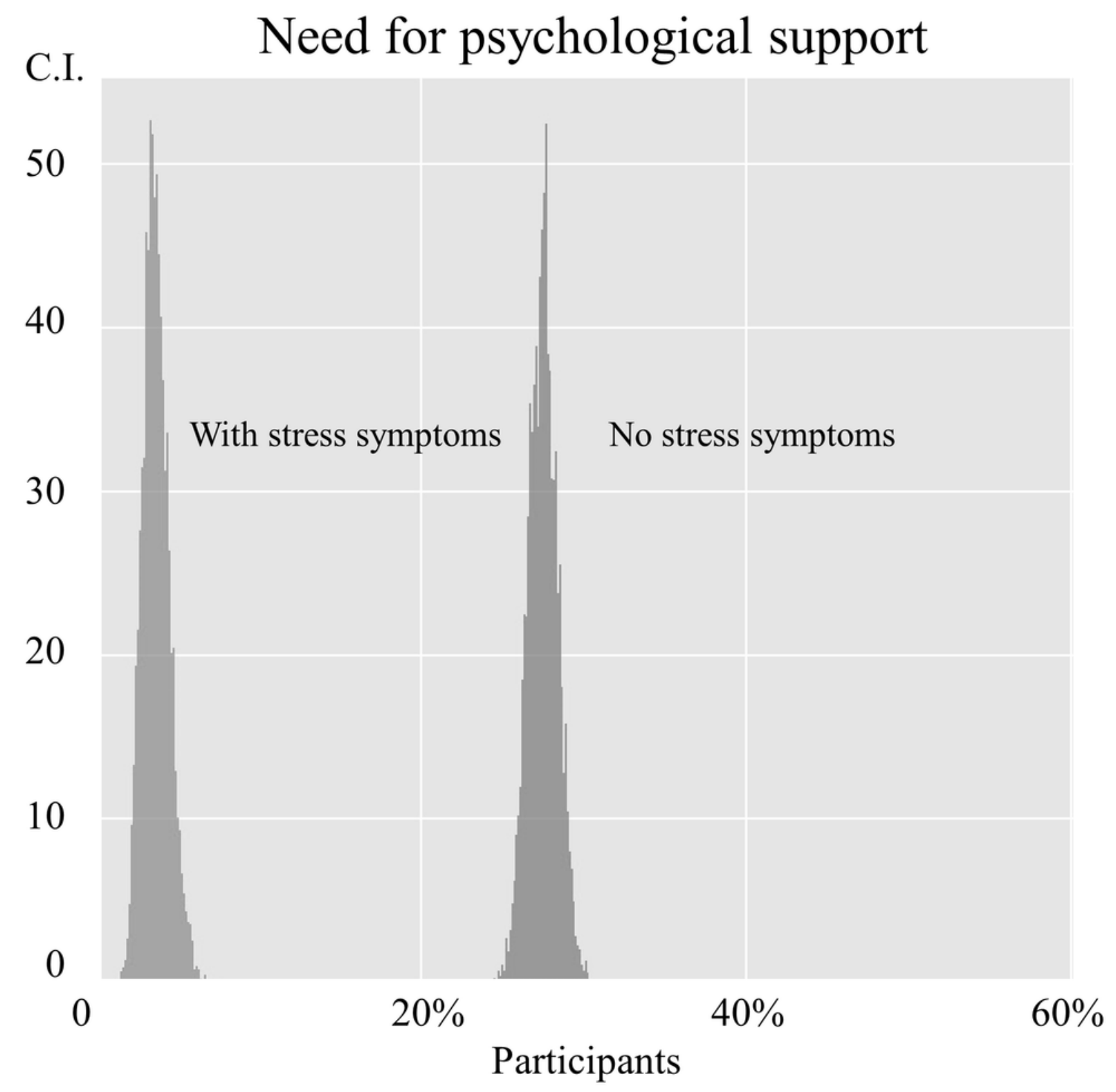

Figure 2

Need for psychological support in participants with and without stress symptoms 


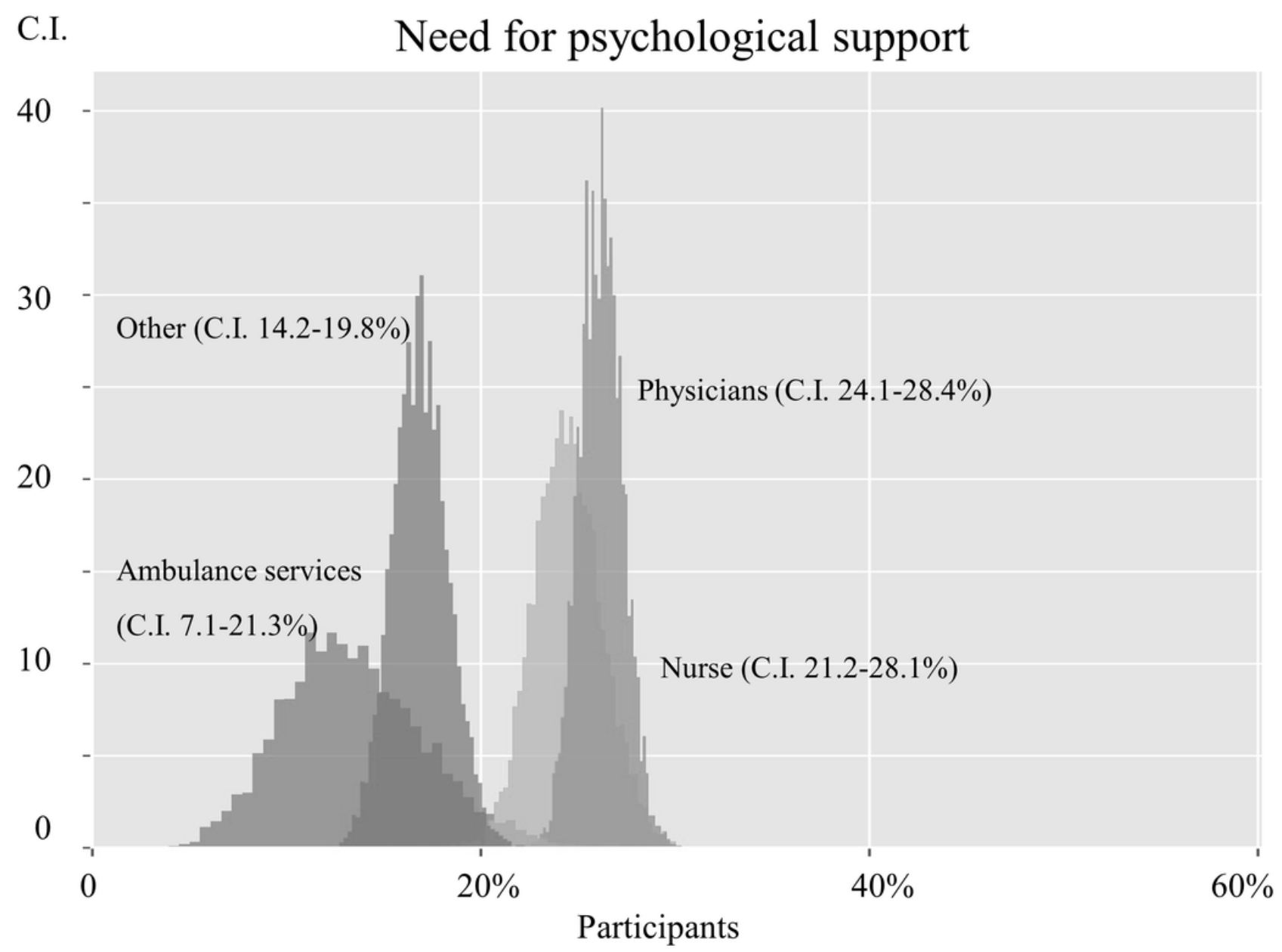

Figure 3

Need for psychological support according to professional categories

\section{Supplementary Files}

This is a list of supplementary files associated with this preprint. Click to download.

- Questionnairesupplmaterial.docx 